\title{
Redox activity and chemical speciation of size fractioned PM in the communities of the Los Angeles-Long Beach harbor
}

\author{
S. Hu${ }^{1}$, A. Polidori ${ }^{1}$, M. Arhami ${ }^{1}$, M. M. Shafer ${ }^{2}$, J. J. Schauer ${ }^{2}$, A. Cho ${ }^{3}$, and C. Sioutas ${ }^{1}$ \\ ${ }^{1}$ University of Southern California, Department of Civil and Environmental Engineering, 3620 South Vermont Avenue, Los \\ Angeles, CA 90089, USA \\ ${ }^{2}$ University of Wisconsin-Madison, Environmental Chemistry and Technology Program, 660 North Park Street, Madison, WI \\ 53706, USA \\ ${ }^{3}$ University of California, Los Angeles, School of Medicine, Los Angeles, CA 90095, USA
}

Received: 25 April 2008 - Published in Atmos. Chem. Phys. Discuss.: 12 June 2008

Revised: 16 September 2008 - Accepted: 25 September 2008 - Published: 12 November 2008

\begin{abstract}
In this study, two different types of assays were used to quantitatively measure the redox activity of PM and to examine its intrinsic toxicity: 1) in vitro exposure to rat alveolar macrophage (AM) cells using dichlorofluorescin diacetate (DCFH-DA) as the fluorescent probe (macrophage ROS assay), and: 2) consumption of dithiothreitol (DTT) in a cell-free system (DTT assay). Coarse ( $\left.\mathrm{PM}_{10-2.5}\right)$, accumulation $\left(\mathrm{PM}_{2.5-0.25}\right.$ ), and quasi-ultrafine (quasi-UF, $\mathrm{PM}_{0.25}$ ) mode particles were collected weekly at five sampling sites in the Los Angeles-Long Beach harbor and at one site near the University of Southern California campus (urban site). All PM samples were analyzed for organic (total and watersoluble) and elemental carbon, organic species, inorganic ions, and total and water-soluble elements. Quasi-UF mode particles showed the highest redox activity at all Long Beach sites (on both a per-mass and per-air volume basis). A significant association $\left(R^{2}=0.61\right)$ was observed between the two assays, indicating that macrophage ROS and DTT levels are affected at least partially by similar PM species. Relatively small variation was observed for the DTT measurements across all size fractions and sites, whereas macrophage ROS levels showed more significant ranges across the three different particle size modes and throughout the sites (coefficients of variation, or CVs, were $0.35,0.24$ and 0.53 for quasi-UF, accumulation, and coarse mode particles, respectively). Association between the PM constituents and the redox activity was further investigated using multiple linear regression models. The results showed that OC was the most important
\end{abstract}

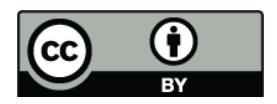

Correspondence to: C. Sioutas (sioutas@usc.edu) component influencing the DTT activity of PM samples. The variability of macrophage ROS was explained by changes in OC concentrations and water-soluble vanadium (probably originating from ship emissions - bunker oil combustion). The multiple regression models were used to predict the average diurnal DTT levels as a function of the OC concentration at one of the sampling sites.

\section{Introduction}

Epidemiological and toxicological studies have shown a positive association between adverse health effects and exposure to fine and ultrafine particulate matter (PM) (Dockery et al., 1993; Pope et al., 2002, 2004). Atmospheric PM and its components have the potential to interact with airway epithelial cells and macrophages to generate reactive oxygen species (ROS), which have been linked to respiratory inflammation and other adverse health effects (Cho et al., 2005; Nel, 2005). A variety of methods in both cell-free and cell-based systems have been employed to examine the oxidative stress activity of PM. Cho et al. (2005) demonstrated that the dithiothreitol (DTT) assay can provide a good measure of the redox activity of particles by determining superoxide radical formation as the initial step in the generation of ROS. Li et al. (2003) showed that the consumption rate of DTT by PM samples is directly related to the particles' ability to induce a stress protein in cells. Other types of in vitro assays are able to assess the ability of PM (or PM extracts) to stimulate cellular generation of ROS in macrophage cells (Sioutas et al., 2005). Despite recent advancements in ROS analysis, the aerosol components driving the formation of ROS remain unclear.

Published by Copernicus Publications on behalf of the European Geosciences Union. 
PM constituents that have been considered as major driving forces for ROS formation include organic species ( $\mathrm{Nel}$ et al., 2001; Seagrave et al., 2005), transition metals (Goldsmith et al., 1998; Prahalad et al., 1999), and polycyclic aromatic hydrocarbons (PAHs) (Kumagai et al., 2002; Li et al., 2003; Cho et al., 2005). Due to the complex chemical compositions of PM, the specific role of different particle species in inducing oxidative stress, whether in non-cellular or cellular assays, is still not well understood and could be assays and/or method dependent.

The link between PM components and their toxicity provides a particularly useful metric for aerosol monitoring, as there is wide agreement among the air pollution community that not all PM species are equally toxic. Ntziachristos et al. (2007a) demonstrated that the DTT activity could be attributed to PAHs via the formation of quinones. Geller et al. (2006) investigated the toxicity of PM emissions from gasoline and diesel passenger cars and demonstrated that a link exists between redox activity and chemical species including organic carbon (OC), low molecular weight PAHs and trace elements such as nickel and zinc. Water soluble metals could also be biologically active and act as catalysts to favor the formation of ROS (Goldsmith et al., 1998; Prahalad et al., 1999; Mudway et al., 2004). However, there are limited studies examining the relationships between the water-soluble PM content and its underlying toxic response.

Efforts have also been made to associate specific sources of PM to oxidative stress (Zhang et al., 2008). However, toxicological studies on the adverse health effects of PM have focused on data collected at limited sampling sites dominated by only a few emission sources (e.g. vehicular emissions) ( $\mathrm{Li}$ et al., 2003), or from laboratory generated aerosols (Su et al., 2008). There are few works conducted to-date examining the toxicity of PM collected at urban areas of interest, including locations impacted by nearby airports, harbors, power plants and refineries. The present study was conducted in the Los Angeles-Long Beach port, which represents the busiest harbor in the US and the fifth most important port complex in the world in terms of commercial activity. This is an area impacted by various sources, including several types of industries, refineries, as well as vehicular and marine vessels. The current work is an extension of a previous study conducted by Ntziachristos et al. (2007a), which addressed redox activity and chemical speciation of size-fractionated PM in urban and rural areas of the Los Angeles Basin. In addition to the DTT assay employed in Ntziachristos et al. (2007a), a macrophage-based ROS assay was also used, and associations between PM components (including water-soluble elements and water-soluble OC) and redox activities were investigated.

\section{Experimental methods}

\subsection{Site locations}

Size-segregated PM samples were collected at four sampling locations in the Los Angeles-Long Beach port area (Site 1-Site 4), at a background location near the harbor of the Los Angeles port (Site 5, the closest to the oceanfront; see Fig. S1 in the supporting information document (http://www.atmos-chem-phys.net/8/6439/ 2008/acp-8-6439-2008-supplement.pdf) for a map of the sampling sites), and at an urban site (Site 6) at the University of Southern California (USC) campus. Samples were collected daily on weekdays (Monday to Friday) over a 7-week period, sequentially, from March to May of 2007. A detailed description of the sampling and chemical analysis methods is described elsewhere (Arhami et al., 2008); only a brief summary is reported here. The six sampling sites were selected to capture the impact of a complex source mix within the harbor community. Sites 1, 2 and 3 were located in Wilmington, West Long Beach. Site 1 was set-up at the intersection between a major street and a local residential road. Site 2 was about $3 \mathrm{~km}$ north of the ocean coast, at the intersection of two major streets, and in close proximity to the Alameda corridor (a $32 \mathrm{~km}$ freight rail "expressway"). Site 3 was located inside a semi-industrial area and less than $1 \mathrm{~km}$ north of the CA-1 highway. Site 4 was further away from the ocean coast ( $\sim 7 \mathrm{~km}$ north), about $1 \mathrm{~km}$ east (downwind) of the I-710 freeway (where more than $25 \%$ of the vehicle fleet is represented by heavy-duty diesel vehicles), and about $1 \mathrm{~km}$ north of the I-405 freeway. Site 5 was a typical background site for the Long Beach harbor, while Site 6 (located at the USC main campus), was representative of urban air quality conditions in downtown Los Angeles.

\subsection{Sampling description}

At each site, size-segregated ambient aerosols were collected using two parallel Sioutas ${ }^{\mathrm{TM}}$ impactors (SKC Inc, PA; operating flow rate $=9 \mathrm{lpm}$ ), one loaded with Zefluor filters ( $3 \mu \mathrm{m}$ pore-size, Pall Life Sciences, Ann Arbor MI) and the other with Quartz fiber filters (Pall Life Sciences, Ann Arbor MI). Three different size fractions of PM were collected, coarse $(2.5 \mu \mathrm{m}<\mathrm{Dp}<10 \mu \mathrm{m})$, accumulation $(0.25 \mu \mathrm{m}<\mathrm{Dp}<2.5 \mu \mathrm{m})$, and quasi-ultrafine $(\mathrm{Dp}<0.25 \mu \mathrm{m})$ modes. All substrate were either baked at $550^{\circ} \mathrm{C}$ (Quartz fiber filter) or cleaned with a series of solvents (Zefluor) before usage to minimize contaminations (see Arhami et al., 2008, for further details). After sampling, each Quartz fiber filter sample was wrapped in a piece of pre-baked aluminum foil, placed in a Petri dish and kept frozen (at $-4^{\circ} \mathrm{C}$ ) until analysis. 


\subsection{Gravimetric and chemical analyses}

Zefluor filters were weighed before and after sampling using a Mettler-Toledo MX5 microbalance (Mettler-Toledo, Columbus, $\mathrm{OH}$; weight uncertainty $\pm 2 \mu \mathrm{g}$ ) in a room with controlled temperature and humidity to determine the mass of the collected PM. Laboratory filter blanks were also weighed before, during, and after each weighing session to verify the accuracy and consistency of the microbalance. The electrostatic charges of the Zefluor substrates were minimized using a static neutralizer (500 $\mu \mathrm{Ci}$ Po210, NRD LLC, Grand Island, NY).

Weekly samples, collected on both Teflon (Zefluor) and quartz fiber filters, were sectioned into four equal parts and analyzed at the Wisconsin State Lab of Hygiene (University of Wisconsin-Madison) for several important inorganic and organic species. Two sets of quartz composites were analyzed by Ion Chromatography (IC) and Thermal Evolution/Optical Transmittance (TOT) to determine the concentrations of inorganic ions (Sheesley et al., 2000), and OC and elemental carbon (EC), respectively (Turpin et al., 2000; Schauer, 2003). The third set of quartz fiber filters was composited for the whole 7-week period at each site and analyzed by Gas Chromatography/Mass Spectrometry (GC/MS) for organic species/tracers including PAHs, n-Alkanes, nAlkanoic Acids, Resin Acids, Hopanes and Steranes (Zheng et al., 2002; Chowdhury et al., 2007) The fourth set of quartz filters was archived for future analysis. Each set of the Zefluor filters was composited into a single sample representing the full 7-week sampling period at each site, and was prepared for the following analysis: (a) Total Elements (b) Water Soluble Elements, and (c) Water Soluble OC (WSOC) and macrophage ROS, and (d) DTT assay. A magnetic sector inductively coupled plasma mass spectrometer (HR-ICPMS, Finnigan Element 2) was applied for the quantification of 52 trace elements (Herner et al., 2006) in the total digests and water extracts. Water extract for total organic carbon (TOC) and ROS analysis were prepared by leaching the PM samples in $900 \mu \mathrm{L}$ of Type 1 water for $16 \mathrm{~h}$ with shaking (Zhang et al., 2008). A General Electric Instrument (Sievers Total Organic Carbon, TOC; GE, Inc.) was used to determine WSOC concentrations (Zhang et al., 2008).

\subsection{Macrophage ROS and DTT assays}

The redox activity of PM was measured by two different types of assays: 1) in-vitro exposure to rat alveolar macrophage (AM) cells using dichlorofluorescin diacetate (DCFH-DA) as the fluorescent probe and 2) consumption of dithiothreitol (DTT) in a cell-free system (DTT assay). The first assay (applied to water soluble extracts of the collected PM filter samples) is directed at the biologically mediated production of ROS within the macrophage cell in response to cell stimulation from "toxic" species. ROS species produced within the cytoplasm de-acetylate the DCFH-DA, resulting in the fluorescing compound (DCFH). Extracellular and abiotic de-acetylation is considered to be small. Hereafter, this assay is referred to as Macrophage ROS. Detailed information about the macrophage ROS analysis is presented by Landreman et al. (2008). Experiments were performed with the rat alveolar cell line, NR8383, maintained in Hams F12 medium containing $2 \mathrm{mM}$ L-glutamine supplemented with $1.176 \mathrm{~g} / \mathrm{L}$ sodium bicarbonate and $15 \%$ heat inactivated fetal bovine serum. Cells were cultured at $37^{\circ} \mathrm{C}$ in a humidified $5 \% \mathrm{CO}_{2}$ incubator and maintained by transferring non-adherent cells to new flasks weekly. Cultures were set up to contain a floating cell concentration of approximately $4 \times 10^{5}$ cells $\mathrm{mL}^{-1}$ of media. For the exposure experiments, cells were harvested and gently concentrated by centrifugation at 750 RPM for $5 \mathrm{~min}$, the culture medium removed, and replaced with a salts-glucose-medium (SGM) to generate a cell suspension of 1000 cells $/ \mu \mathrm{L}$. A $15 \mathrm{mM}$ stock solution of $2^{\prime} 7^{\prime}$-dichlorodihydrofluorescein diacetate (DCFH-DA, Sigma), prepared in $\mathrm{N}, \mathrm{N}^{\prime}$-dimethyl formamide, was diluted 10 fold in SGM just prior to use. One hundred $\mu \mathrm{L}$ of the macrophage cell suspensions were dispensed into each well of a 96 well plate and incubated at $37^{\circ} \mathrm{C}$ for two hours. Approximately $15 \mathrm{~min}$ before the end of the incubation period, the diluted DCFH-DA solution was added to each prepared sample extract to achieve a final concentration of $15 \mu \mathrm{M}$ DCFH-DA. After the incubation period, during which time $>98 \%$ of the cells settled and adhered to the well bottom, the SGM was pipetted off and immediately replaced with $100 \mu \mathrm{L}$ of SGM-buffered sample extract or control sample. The fluorescence intensity in each well was determined at $450 \pm 50$ excitation and $530 \pm 25$ emission using a CytoFlour II automated fluorescence plate reader (PerSeptive Biosystems) at regular intervals throughout the exposure period (typically $2.5 \mathrm{~h}$ ). For each exposure experiment several untreated and method blank controls were included. Unopsonized zymosan was included as a positive control. Each sample/dilution was run in triplicate (i.e. 3 wells each).

The DTT assay (applied to suspensions of the collected particles) provides an estimate of the redox activity of a sample based on the ability of the PM to catalyze electron transfer between DTT and oxygen in simple chemical systems (Cho et al., 2005). The electron transfer is monitored by the rate at which DTT is consumed under a standardized set of conditions and the rate is proportional to the concentration of the catalytically redox-active species in the PM sample as well as their rate constants for the reaction with DTT. This chemical assay measures the consumption of DTT that is capable of quantitatively determining superoxide radical formation as the first step in the generation of ROS. The methodological procedure used for the DTT assays conducted for this work is described in great detail by Cho et al. (2005) and $\mathrm{Li}$ et al. (2003). In brief, the Zefluor filters were sonicated in Milli-Q water for $20 \mathrm{~min}$. The filters were then removed and the aqueous particle suspension was used in the DTT assay. The PM suspension was 
Table 1. Size-resolved PM mass concentration, chemical composition and redox activities at the six sampling sites.

\begin{tabular}{|c|c|c|c|c|c|c|c|c|c|c|c|c|}
\hline Size & Site & $\begin{array}{c}\text { Mass } \\
\left(\mu \mathrm{g} / \mathrm{m}^{3}\right)\end{array}$ & $\begin{array}{l}\text { OC } \\
(\%)\end{array}$ & $\begin{array}{l}\mathrm{EC} \\
(\%)\end{array}$ & $\begin{array}{c}\mathrm{SO}_{4}^{2-} \\
(\%)\end{array}$ & $\begin{array}{c}\mathrm{NO}_{3}^{-} \\
(\%)\end{array}$ & $\begin{array}{l}\mathrm{Na}^{+} \\
(\%)\end{array}$ & $\begin{array}{c}\mathrm{NH}_{4}^{+} \\
(\%)\end{array}$ & $\begin{array}{l}\mathrm{K}^{+} \\
(\%)\end{array}$ & $\begin{array}{l}\text { Metals \& } \\
\text { Elements } \\
\quad(\%)\end{array}$ & $\begin{array}{c}\text { DTT } \\
\left(\mathrm{nmol} \mathrm{min}^{-1 /}\right. \\
\mu \mathrm{g} \mathrm{PM})\end{array}$ & $\begin{array}{c}\text { Macrophage ROS } \\
(\mu \mathrm{g} \text { Zymosan Units/ } \\
\mu \mathrm{g} \mathrm{PM})\end{array}$ \\
\hline \multirow{3}{*}{ Quasi-UF } & $\mathrm{S} 2$ & 6.3 & 38.9 & 12.0 & 13.2 & 3.7 & 0.8 & 5.8 & 0.2 & 4.5 & 0.032 & 0.353 \\
\hline & S3 & 5.2 & 35.1 & 13.1 & 17.9 & 3.8 & 1.6 & 7.2 & 0.3 & 6.9 & 0.047 & 0.393 \\
\hline & S4 & 5.0 & 38.1 & 7.9 & 15.7 & 6.2 & 0.7 & 7.1 & 0.3 & 3.9 & 0.055 & 0.312 \\
\hline \multirow{5}{*}{ Accumulation } & S1 & 5.5 & 13.5 & 2.8 & 29.2 & 12.6 & 6.3 & 9.1 & 0.5 & 11.2 & 0.024 & 0.180 \\
\hline & S2 & 7.5 & 12.7 & 1.5 & 25.3 & 14.5 & 7.6 & 8.4 & 0.5 & 13.2 & 0.018 & 0.123 \\
\hline & S3 & 6.6 & 14.0 & 2.4 & 26.1 & 14.0 & 6.5 & 9.0 & 0.5 & 14.1 & 0.023 & 0.216 \\
\hline & S4 & 8.8 & 12.5 & 1.4 & 25.2 & 18.1 & 6.8 & 9.2 & 0.4 & 8.7 & 0.014 & 0.118 \\
\hline & S5 & 4.8 & 12.8 & 1.4 & 21.3 & 14.2 & 10.9 & 5.8 & 0.5 & 19.1 & 0.020 & 0.136 \\
\hline \multirow[t]{3}{*}{ Coarse } & S4 & 12.5 & 7.5 & 1.3 & 5.3 & 16.3 & 12.0 & 1.5 & 0.5 & 9.2 & 0.012 & 0.065 \\
\hline & S5 & 7.1 & 5.5 & 0.9 & 6.1 & 17.8 & 16.9 & 0.9 & 0.6 & 17.6 & 0.008 & 0.097 \\
\hline & S6 & 8.5 & 8.6 & 0.6 & 5.7 & 22.9 & 10.5 & 2.8 & 0.5 & 10.1 & 0.012 & 0.075 \\
\hline
\end{tabular}

*Outlier

incubated at $37^{\circ} \mathrm{C}$ with DTT $(100 \mu \mathrm{M})$ in potassium phosphate $(0.1 \mathrm{M})$ buffer at $\mathrm{pH} 7.4$ (1 mL total volume) for times varying from 0 to $30 \mathrm{~min}$. Trichloroacetic acid $(10 \%, 1 \mathrm{~mL})$ was added to the incubation mixture to quench the reaction at preset times. An aliquot of the quenched reaction mixture was then mixed with Tris- $\mathrm{HCl},(0.4 \mathrm{M}, 1 \mathrm{~mL}, \mathrm{pH} 8.9)$ that contains EDTA $(20 \mathrm{mM})$ and DTNB $(10 \mathrm{mM}, 25 \mu \mathrm{L})$. The remaining DTT was measured by the formation of 5mercapto-2-nitrobenzoic acid.

\subsection{Statistical data analysis}

Bivariate Pearson Correlations between Macrophage ROS and DTT levels, and the concentrations of the chemically speciated PM were calculated for a preliminary identification of the most important predictor variables that could be included in multiple regression models for macrophage ROS and DTT. The chemical species with a significantly positive correlation $(p<0.05)$ with the macrophage ROS and DTT concentrations were then chosen as predictors in a series of multiple linear regression analyses (i.e. stepwise, forward, and backward elimination selections) using SAS for Windows (V 9.1, SAS Inc., Cary, NC). A general multiple linear regression equation expresses the response variable $\left(\boldsymbol{Y}_{i}\right)$ as a linear combination of $(p-1)$ predictor variables $\left(\boldsymbol{X}_{i}\right)$ :

$Y_{i}=\beta_{0}+\beta_{1} X_{i, 1}+\beta_{2} X_{i, 2}+\ldots . .+\beta_{p-1} X_{i, p-1}+\varepsilon_{i}$ where, $Y_{i}$ is the response in the $i$-th trial (i.e. Macrophage ROS or DTT), $\beta_{0}, \beta_{1}, \ldots, \beta_{p-1}$ are the regression coefficients, $X_{i, 1}, X_{i, 2}, \ldots, X_{i, p-1}$ are predictor variables (i.e. inorganic and organic species and trace elements), and $\varepsilon_{i}$ is the error term.

\section{Results and discussion}

\subsection{Overview of the PM chemical speciation}

Table 1 shows the concentration of PM in three particle size ranges at each sampling site, and the corresponding percentage contribution of major aerosol components to PM mass. A detailed discussion about the chemical speciation results is described elsewhere (Arhami et al., 2008). The mass distribution of the different species in different size fractions was relatively homogeneous across sampling sites. OC was the most abundant component of quasi-ultrafine (quasi-UF) particles at all sites (31.0 to $38.9 \%$ at Site 5 and Site 2, respectively). The organic material in ultrafine particles predominantly originates from various combustion sources (Seinfeld and Pandis, 1998), such as vehicular and ship emissions. OC in the accumulation mode may also originate from the photo-oxidation of reactive gaseous precursors (i.e. secondary organic aerosol, or SOA, formation) (Turpin et al., 2000; Polidori et al., 2006). EC, primarily formed from incomplete combustion processes and often considered to be 
a good surrogate of diesel emissions (Seinfeld and Pandis, 1998), was present mainly in the quasi-UF mode (7.9 to $13.5 \%$ at Site 4 and Site 1 , respectively).

Secondary aerosol components, such as sulfate, nitrate and ammonium, were the most dominant species in accumulation mode particles, together accounting between $41.2 \%$ (Site 5) and $60.0 \%$ (Site 6) over the six sampling sites. Sulfate was the most abundant component in the accumulation mode ( 21.3 to $29.2 \%$ at Site 5 and Site 1 , respectively) and the second most abundant component following OC in the quasi-UF mode (13.2 to $20 \%$ at Site 2 and Site 5, respectively) at most sites. Accumulation mode sulfate is mainly present in the urban air as ammonium sulfate, a secondary aerosol component formed in the atmosphere through the oxidation of sulfur dioxide (Rodhe, 1999), whereas in the quasi-UF fraction, a significant part of sulfate also originates from bunkerfuel combustion from the nearby marine port vessels (Lin et al., 2005; Arhami et al., 2008). Nitrate contributed mostly to the mass of accumulation mode (12.6 to $24.8 \%$ at Site 1 and Site 6, respectively) and coarse mode particles (11.2 to $23.4 \%$ at Site 2 and Site 1, respectively). In the accumulation mode, nitrate originates through secondary processes involving nitric acid and ammonia (Seinfeld and Pandis, 1998), while in the coarse fraction it is mostly formed from reactions between nitric acid and sea salt or mineral compounds (Kerminen et al., 1998; Pio and Lopes, 1998). Ammonium $\left(\mathrm{NH}_{4}^{+}\right)$, present in the atmosphere mainly as ammonium nitrate and ammonium sulfate, is also formed through secondary processes from gaseous precursor, and typically contributed more to the mass of accumulation mode PM (5.8 to $11.7 \%$ at Site 5 and Site 6, respectively). Table S1 (supporting information at http://www.atmos-chem-phys.net/8/6439/ 2008/acp-8-6439-2008-supplement.pdf) shows weekly averages ( \pm standard deviations) of the PM mass and of major chemical components at each site and for 3 different size fractions: quasi-ultrafine (quasi-UF), accumulation (ACC), and coarse particles. Overall, standard deviations are relatively small compared to the corresponding averaged levels, suggesting insignificant week-to-week variability of the concentrations of the PM mass and of the major chemical species measured at each site over the entire sampling campaign. This might be mostly because of the stable meteorological conditions and the constant influence of vehicular sources over the entire sampling period (Arhami et al., 2008).

Trace elements accounted from 9.2 to $17.6 \%$ of the coarse particle mass, and between 7.5 and $19.1 \%$ of the accumulation mode mass. Their contribution to the quasi-UF fraction was relatively lower (3.9 to 6.9\%) at all sites. $\mathrm{Na}$ and $\mathrm{S}$ were the most abundant elements in all three size fractions, followed by $\mathrm{Ca}, \mathrm{Mg}, \mathrm{K}, \mathrm{Fe}$ and $\mathrm{Al}$. Among all elements, Al, Fe, $\mathrm{Ti}, \mathrm{K}, \mathrm{Mn}$, and $\mathrm{Cs}$, which have a crustal origin (Ntziachristos et al., 2007b; Arhami et al., 2008) and are products of re-suspended soil dust, were found mostly in coarse PM. Sb, $\mathrm{S}, \mathrm{Cd}, \mathrm{Mo}, \mathrm{Zn}, \mathrm{Pb}$ and $\mathrm{Cu}$, mainly generated by vehicular sources and present as constituents of lube oil (Ntziachris- tos et al., 2007b), were found in all size fractions. V and $\mathrm{Ni}$, which are mostly emitted by marine vessels and oil combustion (Isakson et al., 2001; Lu et al., 2006), were more abundant in the quasi-UF mode.

\subsection{Water-soluble elements and water-soluble organic car- bon (WSOC) content}

Figure 1 shows water-soluble elements as a fraction of total element concentration in the three size ranges. Generally, trace elements in quasi-UF and accumulation mode particles are more soluble than those in coarse PM. For certain elements, in particular for $\mathrm{Cd}, \mathrm{Zn}, \mathrm{Sb}, \mathrm{Ni}, \mathrm{Li}, \mathrm{Co}$, and $\mathrm{Cu}$, the solubility is highest in quasi-UF PM (>0.75) and decreases with increasing particle size. It should be noted that few elements (such as $\mathrm{Cd}, \mathrm{Zn}$ and $\mathrm{Na}$ ) showed a water-soluble fraction greater than 1 (between 1 and 1.6), which might be due to the analytical uncertainty. This class of compounds might originate from high temperature combustion processes, such as fresh vehicular emissions. $\mathrm{Zn}$ and $\mathrm{Cd}$ are almost entirely water-soluble in both quasi-UF and accumulation modes. $\mathrm{Na}$ showed very high and comparable water solubility among the three size ranges. The solubility of $\mathrm{Ba}, \mathrm{Mo}, \mathrm{Mn}, \mathrm{V}, \mathrm{Mg}, \mathrm{Cs}$, $\mathrm{Pb}$ and $\mathrm{K}, \mathrm{Sr}$ peaked in the accumulation mode. The least soluble elements were $\mathrm{Cr}, \mathrm{Fe}, \mathrm{Al}, \mathrm{Ce}, \mathrm{La}$ and $\mathrm{Ti}(<15 \%)$, a finding consistent with their geochemical origin. These results agree with those reported in other studies conducted in an urban area of Birmingham, UK (Heal et al., 2005; Birmili et al., 2006). Birmili et al. (2006) reported that $\mathrm{Zn}$ and $\mathrm{Cd}$ in ambient $\mathrm{PM}_{7.2}$ particles are the most soluble trace elements ( $~ 50 \%$ ), followed by $\mathrm{Mn}, \mathrm{Cu}, \mathrm{Ba}, \mathrm{Pb}$ and $\mathrm{Co}$.

Figure 2 shows water-soluble (WSOC) and waterinsoluble OC (WIOC) concentrations in three size ranges at all sampling sites. While some WSOC originates from primary emission sources, such as biomass burning, its production is mostly attributed to SOA formation processes (Weber et al., 2007). The highest WSOC concentrations were in fine PM at all sites, with relatively equal partitioning between quasi-UF and accumulation modes (site-average WSOC concentrations were $0.25 \pm 0.08$ and $0.20 \pm 0.12 \mu \mathrm{g}$ $\mathrm{C} / \mathrm{m}^{3}$ for quasi-UF and accumulation modes, respectively). The average percentage contributions of WSOC to measured OC across all sites were $13.3 \pm 4.0 \%, 22.1 \pm 10.8 \%$ and $16.6 \pm 11.9 \%$ for quasi-UF, accumulation and coarse mode particles, respectively, consistent with WSOC/OC wintertime ratios measured at other locations (Miyazaki et al., 2006). The relatively low WSOC/OC values as well as absolute WSOC concentrations compared to those reported in other studies are reflective of the limited photochemical activity during our sampling period. Decesari et al. (2001) observed seasonal variations in WSOC/OC ratio from 0.38 (winter) to 0.50 (summer) for fine particles $(\mathrm{Dp}<1.5 \mu \mathrm{m})$ in the Po Valley. Sullivan and Weber (2006) reported mean WSOC/OC ratios for $\mathrm{PM}_{2.5}$ particles in the range of 0.50 and 0.60 in winter and summer, respectively, for measurements in 


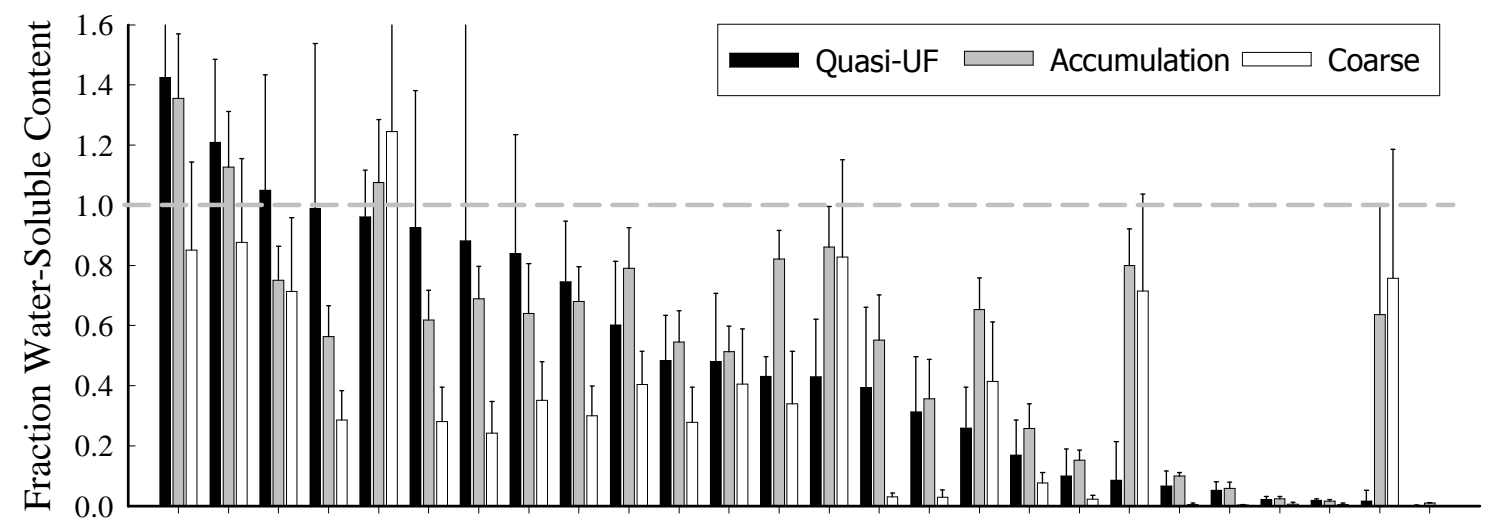

Cd Zn S Sb Na Ni Li Co Cu Ba MoMn V Mg Cs Pb K Rb Cr Sr Fe Al Ce La Ca Ti

Water-Soluble Elements

Fig. 1. Mean fractions of water-soluble elements in each size range. Error bars are the standard deviation of measurements obtained over the sampling sites.

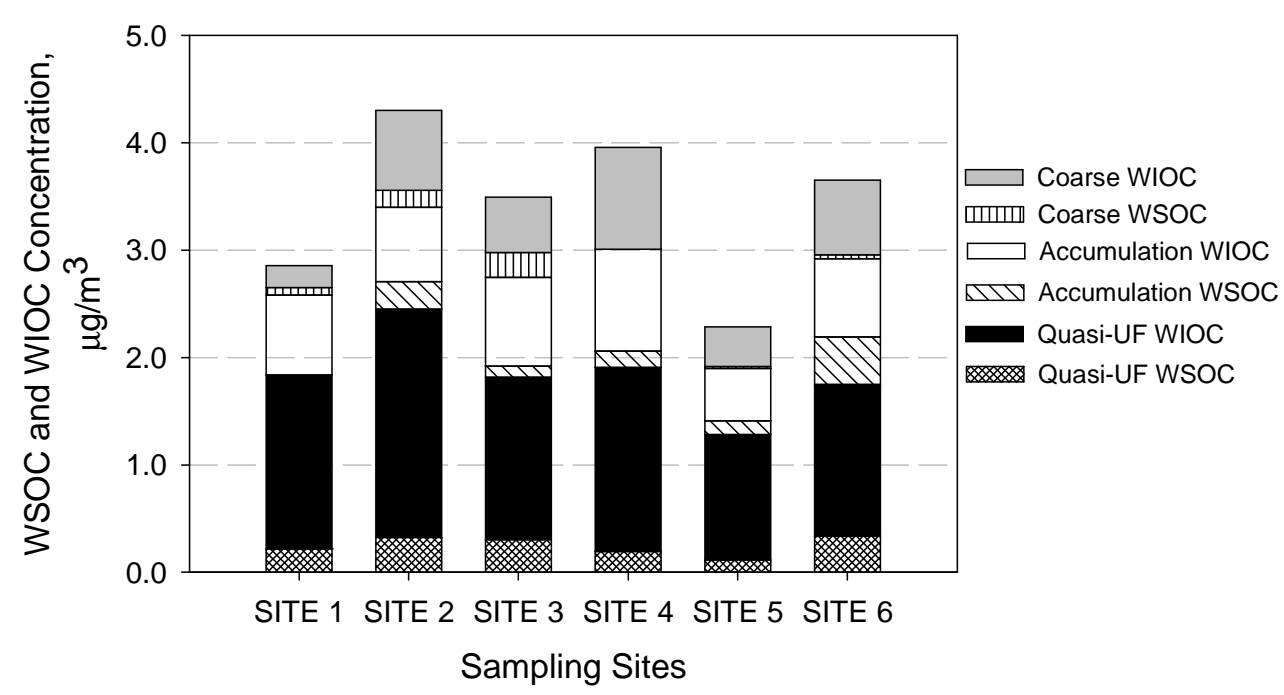

Fig. 2. Concentrations of water-soluble organic carbon (WSOC) and water insoluble organic carbon (WIOC) in three size ranges at all sampling sites.

St. Louis, MO, and Atlanta, GE. Ruellan and Cachier (2001) observed low mean WSOC/OC values (0.13) near a highly trafficked road around Paris in the summer and fall.

During this study, the highest WSOC concentrations as well as WSOC/OC fractions were observed at Site 6 (downtown LA). This site is a receptor of freshly emitted particles upwind in the harbor area and transported to that site after considerable atmospheric aging (Site 6 is approximately $40 \mathrm{~km}$ north, thus mostly downwind, of the harbor sites). Ho et al. (2006) reported that the WSOC/OC fraction in $\mathrm{PM}_{2.5}$ measured in Hong Kong was lower at an urban site than at urban-residential and background sites, due to the formation of SOA during transport/aging of the PM mass from urban to background sites.

\subsection{Measured redox activities}

The redox activities of size fractionated PM measured by the two assays are shown, for all sites, on a per PM mass basis in Table 1. The macrophage ROS level of quasi-UF particles measured at Site 1 was extremely high compared to those obtained in the same size-range at other sites. We do not have an obvious explanation for the higher PM activity in that site, at lest based on the detailed chemical PM composition discussed in earlier paragraphs. We thus treated this data point as an outlier in the statistical analysis described in subsequent sections. On a per mass basis, ultrafine particles exhibited significantly higher redox activity than fine and coarse mode PM. Few previous studies have demonstrated 
this size-dependent contrast in PM toxicity ( $\mathrm{Li}$ et al., 2003; Cho et al., 2005; Ntziachristos et al., 2007a). We also investigated the redox potential of PM on a per unit of air volume basis (Fig. 3a), and quasi-UF particles still showed the highest activity levels at all Long Beach sites (Sites 1-5), but not at Site 6 (urban site near USC), where accumulation mode particles had higher toxicity measured by the macrophage ROS assay.

The average DTT activities for $\mathrm{PM}_{2.5}$ particles at the Long Beach sites $(0.027 \pm 0.004 \mathrm{nmol} \mathrm{DTT} / \mathrm{min} / \mu \mathrm{g}$ mass; individual values for each site are reported in Table 1 on a per PM mass basis, and on Fig. $3 \mathrm{~b}$ on a per unit of air volume basis) are well in the range of those reported for $\mathrm{PM}_{2.5}$ particles in a previous study conducted during different seasons at different urban areas in Southern California (Ntziachristos et al., 2007a) $(0.027 \pm 0.005 \mathrm{nmol} \mathrm{DTT} / \mathrm{min} / \mu \mathrm{g}$ mass $)$. The average DTT activity of $\mathrm{PM}_{0.25}(0.039 \pm 0.010 \mathrm{nmol} \mathrm{DTT} / \mathrm{min} / \mu \mathrm{g}$ mass) in this study is somewhat lower than that of $\mathrm{PM}_{0.15}$ $(0.058 \pm 0.015 \mathrm{nmol} \mathrm{DTT} / \mathrm{min} / \mu \mathrm{g}$ mass$)$ estimated by Ntziachristos et al. (2007a). This discrepancy is probably due to the relatively lower contribution of particles between 0.15 and $0.25 \mu \mathrm{m}$ to the DTT activity on a per mass basis.

The variability of the redox potential among size-fractions was estimated by its coefficient of variation $(\mathrm{CV}$; the standard deviation to mean ratio). CVs for DTT activities were $0.25,0.20$ and 0.27 for quasi-UF, accumulation and coarse mode PM, respectively. This rather low variability could be attributed to the fairly homogenous distribution of organic species on a per mass basis among the three size ranges in that area. As it will be discussed later, these species are mostly responsible for the variability in DTT. By contrast, higher CVs were observed for macrophage ROS $(0.35,0.24$ and 0.53 , for quasi-UF, accumulation and coarse mode particles, respectively.

\subsection{DTT vs. macrophage ROS}

DTT activities and macrophage ROS measurements are compared on Fig. S2 (supporting information). Macrophage ROS is significantly correlated with DTT consumption $\left(R^{2}=0.61\right.$, $p<0.05$ ) for the pooled samples (17 data points; as stated previously quasi-UF ROS at Site 1 was excluded from all calculations). It should be noted that these are two independent and intrinsically different assays and, thus, should not be expected to be correlated a priori. The consumption of DTT is based on the ability of a PM sample to accept electrons from DTT and transfer them to oxygen (Cho et al., 2005); whereas macrophage ROS assays use a filtered extract, so that cells are exposed to the soluble components of PM only. DCFH is a broad spectrum ROS probe, directly responsive to most common reactive oxygen species, including the hydroxyl radical, peroxide, superoxide radical, and peroxynitrite radical and, therefore, provides a more comprehensive, less targeted, assessment of the redox activity of PM. For example, the ROS produced by many redox active metals, will

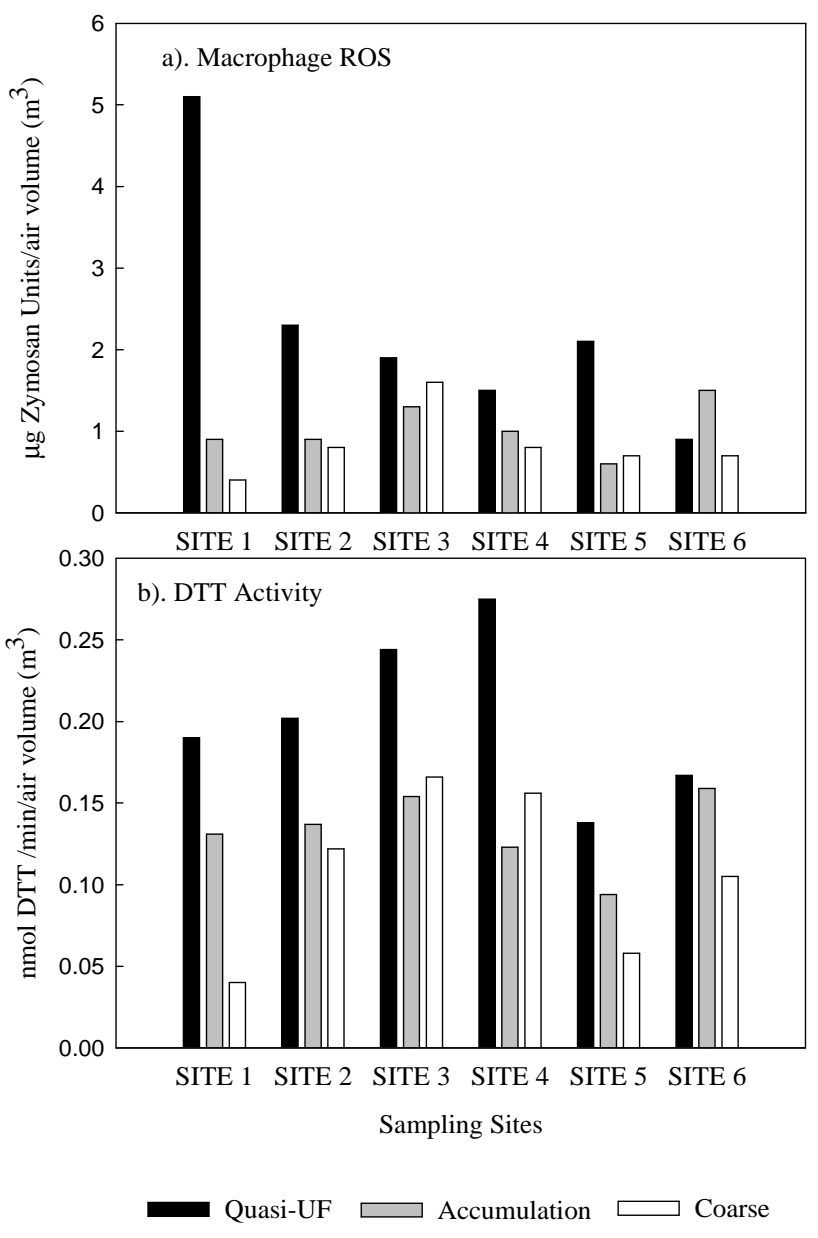

Fig. 3. Spatial distribution of size fractioned redox activities at the Long Beach harbor; (a) Macrophage ROS assay and (b) DTT assay.

be addressed by the DCFH, while the DTT assay is relatively insensitive to this mechanism. In many respects the two assays are quite complementary. The DTT method is strictly a chemical probe, especially sensitive to many organic functionalities (e.g. quinines), while the DCFH approach, fundamentally a cell-based method, probes the general oxidative stress imposed by PM on a living organism. The substantial correlation between these two assays suggests that both analyses may be driven, at least in part, by variations in the concentrations of similar chemical species. The association between the DTT and Macrophage ROS assay and PM constituents are further investigated in the following sections.

\subsection{Macrophage ROS/DTT vs. chemical speciation}

Table 2 shows Pearson's correlation coefficients of macrophage ROS and DTT vs selected PM components. All data points obtained in the three size ranges at the six sampling sites were pooled to calculate the resulting mean Pearson's coefficients and $\mathrm{p}$ values. The species with 
Table 2. Pearson correlation between macrophage ROS activity, DTT level, and selected species.

\begin{tabular}{llrrrr}
\hline \multirow{2}{*}{ Species } & \multicolumn{2}{c}{ Macrophage ROS } & \multicolumn{2}{c}{ DTT } \\
& & $R$ & $p$ & $R$ & $p$ \\
\hline \multirow{4}{*}{ Ions } & $\mathrm{SO}_{4}^{2-}$ & 0.26 & 0.31 & 0.27 & 0.30 \\
& $\mathrm{NO}_{3}^{-}$ & -0.71 & 0.00 & -0.74 & 0.00 \\
& $\mathrm{Na}^{+}$ & -0.67 & 0.00 & -0.80 & 0.00 \\
& $\mathrm{NH}_{4}^{+}$ & 0.29 & 0.25 & 0.38 & 0.13 \\
& $\mathrm{~K}^{+}$ & -0.56 & 0.02 & -0.53 & 0.03 \\
\hline \multirow{5}{*}{ Carbonaceous species } & $\mathrm{EC}$ & 0.75 & 0.00 & 0.82 & 0.00 \\
& $\mathrm{OC}$ & 0.81 & 0.00 & 0.91 & 0.00 \\
& $\mathrm{WSOC}$ & 0.69 & 0.007 & 0.67 & 0.005 \\
& $\mathrm{PAHs}(\mathrm{MW}<=228)$ & 0.75 & 0.00 & 0.79 & 0.00 \\
& $\mathrm{Levoglucosan}$ & 0.40 & 0.11 & 0.52 & 0.03 \\
\hline & $\mathrm{Al}$ & 0.50 & 0.04 & 0.62 & 0.01 \\
& $\mathrm{~S}$ & 0.53 & 0.03 & 0.50 & 0.04 \\
& $\mathrm{~V}$ & 0.94 & 0.00 & 0.76 & 0.00 \\
& $\mathrm{Cr}$ & 0.49 & 0.05 & 0.69 & 0.00 \\
& $\mathrm{Co}$ & 0.56 & 0.02 & 0.65 & 0.01 \\
& $\mathrm{Ni}$ & 0.93 & 0.00 & 0.78 & 0.00 \\
& $\mathrm{Zn}$ & 0.50 & 0.04 & 0.47 & 0.06 \\
& $\mathrm{~Pb}$ & 0.64 & 0.01 & 0.72 & 0.00 \\
& $\mathrm{Mo}$ & 0.63 & 0.01 & 0.78 & 0.00 \\
& $\mathrm{Sb}$ & 0.17 & 0.52 & 0.46 & 0.06 \\
& $\mathrm{Pt}$ & 0.14 & 0.60 & 0.48 & 0.05 \\
& $\mathrm{Fe}$ & 0.13 & 0.63 & 0.18 & 0.48 \\
& $\mathrm{Cu}$ & 0.42 & 0.09 & 0.32 & 0.21 \\
\hline
\end{tabular}

a significantly positive correlation $(p<0.05)$ with the redox activities are highlighted in bold in the table. Inorganic ions show insignificant or negative correlation with both assays, which agrees with the findings of other studies (Ntziachristos et al., 2007a). Nitrate and sulfate have no functional groups to result in the formation of ROS, but may play a general role on particle toxicity by affecting PM acidity. OC showed a significant correlation with both assays. EC is also significantly correlated with both macrophage ROS and DTT levels, but this strong association may be due to the high correlation between EC and OC concentrations, both being emitted mostly by motor-vehicles. As shown in Table S2 (supporting information http://www.atmos-chem-phys.net/ 8/6439/2008/acp-8-6439-2008-supplement.pdf), a strong correlation of water soluble $\mathrm{V}$ and $\mathrm{Ni}$ with macrophage ROS was observed, with $\mathrm{R}$ values of 0.94 and 0.93 , respectively. These two trace elements were highly correlated in this study (Arhami et al., 2008), suggesting that they originated from bunker fuel combustion from marine vessels (Isakson et al., 2001). With the exception of $\mathrm{V}, \mathrm{Ni}$ and few other elements, the other species are moderately, insignificantly ( $p>0.05$ ) or negatively correlated with both ROS and DTT assays (Table S3, see supporting information for details).
Figure 4 show correlations between a selected group of PM components (expressed as a percentage of the measured PM mass) and redox activities of PM measured by the macrophage ROS (Fig. 4a) and DTT (Fig. 4b) assays. The corresponding regression slopes, intercepts, and correlation coefficients $\left(R^{2}\right)$ are summarized in Table S4 (supporting information). Water soluble $\mathrm{V}$ and, to a lesser degree, light molecular weight PAHs $(\mathrm{MW} \leq 228)$ and $\mathrm{OC}$ are well correlated with macrophage ROS levels. With the exception of one data point (quasi-UF at Site 5), WSOC was also well correlated with $\operatorname{ROS}\left(R^{2}=0.69\right.$, after excluding the influence of this last measurement). We hypothesize that the relative higher macrophage ROS level of quasi-UF particles at Site 5 is mostly driven by the abundance of water soluble $\mathrm{V}\left(4.5 \mathrm{ng} / \mathrm{m}^{3}\right)$ and $\mathrm{Ni}\left(1.2 \mathrm{ng} / \mathrm{m}^{3}\right)$, rather than water soluble $\mathrm{OC}$, given the proximity of the site to the port and the lack of notable traffic sources nearby. OC had the highest correlation with DTT than any other PM species (Fig. 4b). A multiple linear regression (MLR) analysis was conducted to further investigate the contribution of the PM chemical components to the measured redox activities. 


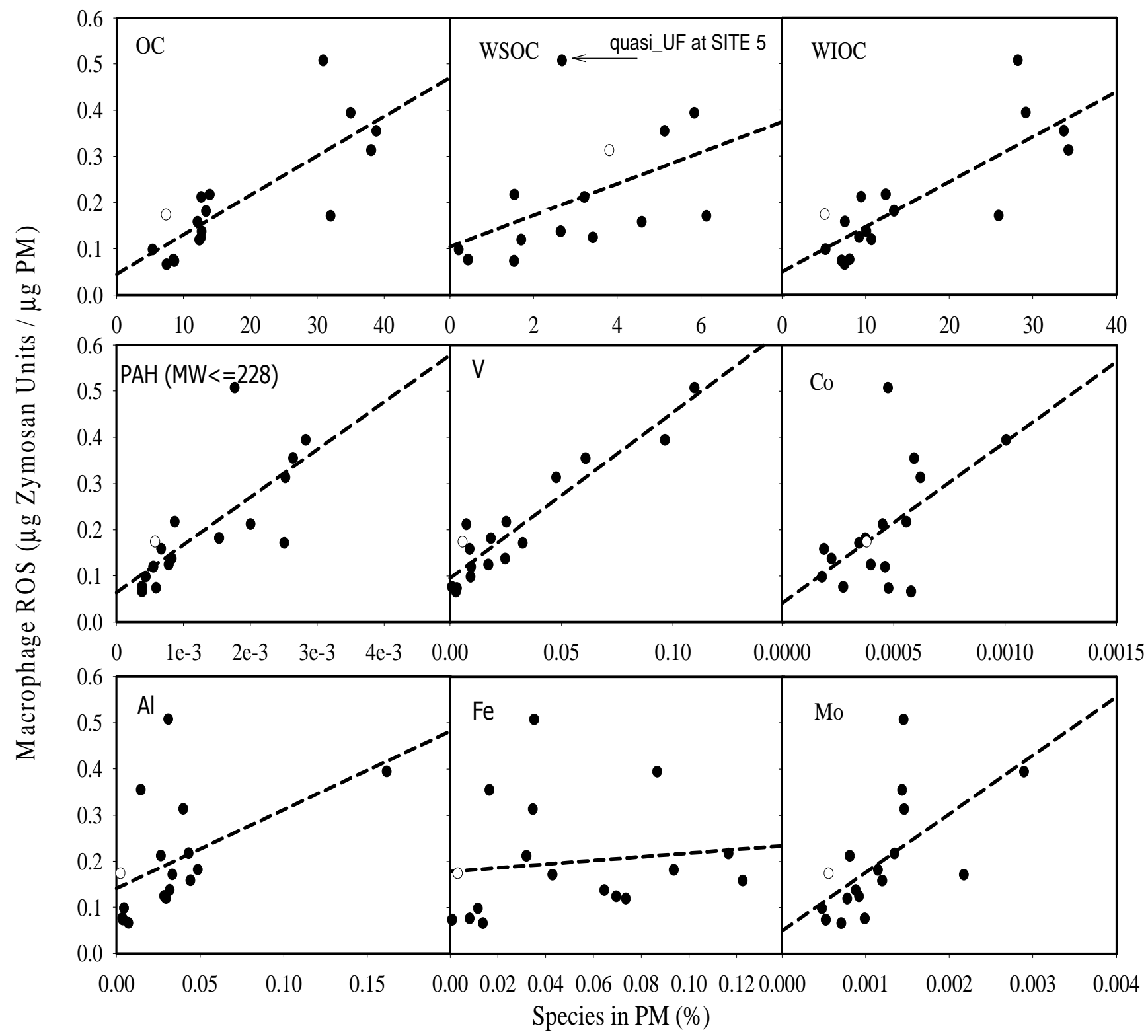

Fig. 4. Scatter Plot of (a) Macrophage ROS and (b) DTT, with total, insoluble and water soluble OC (OC, WIOC, and WSOC, respectively) and selected water soluble elements. Open circles represent the non-fitting points for multiple regression models.

\subsection{Multi-variance analysis}

\subsection{1 "Best-fitting" model for DTT}

The "best-fitting" (3-parameters) regression equation for the DTT concentration was obtained using a "forward" selection method in SAS ("PROC REG"):

$$
\begin{aligned}
\mathrm{DTT}= & 0.034+5.585 \times 10^{-02} \cdot \mathrm{OC}+9.15^{E-06} \\
& \cdot \mathrm{Al}_{\text {soluble }}+7.39 \times 10^{-04} \cdot \mathrm{Co}_{\text {soluble }}
\end{aligned}
$$

where, $\mathrm{OC}, \mathrm{Al}_{\text {soluble }}$ and $\mathrm{Co}_{\text {soluble }}$ are measured concentrations of $\mathrm{OC}$, water-soluble $\mathrm{Al}$ and water-soluble $\mathrm{Co}$, respec- tively. The model was run considering all of the quasi-ultrafine, accumulation and coarse concentrations together (a total of 16 data-points; 2 outliers were found and excluded), and the correlation between predicted and measured DTT was excellent $(\mathrm{y}$ [predicted DTT] $=0.95 \mathrm{X}$ [measured DTT]+0.0076); $\left.R^{2}=0.95\right)$.

As shown in Table S5a (supporting information http://www.atmos-chem-phys.net/8/6439/2008/ acp-8-6439-2008-supplement.pdf), OC is by far the most significant factor in the regression (partial $R^{2}=0.76$ ). The overall model is statistically significant $(p<0.0001)$, has an $R^{2}$ of 0.95 , and a parameter coefficient (Cp) of 4 (the 


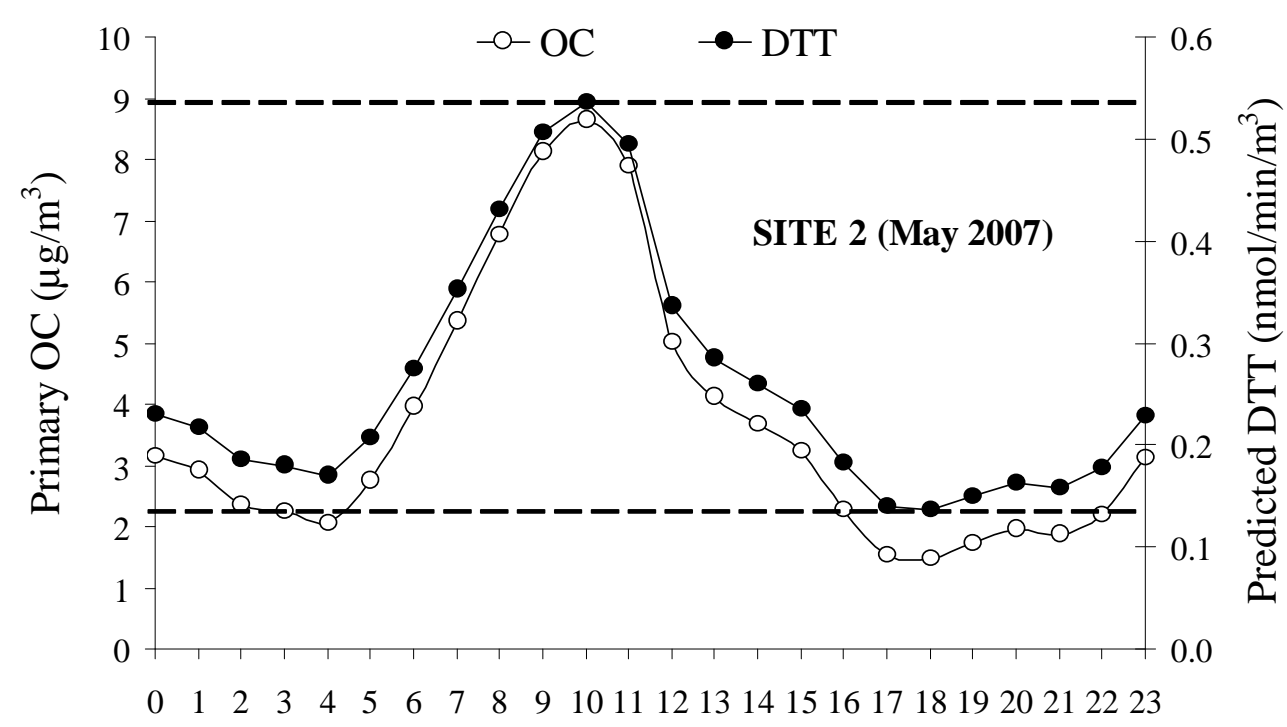

Time (hr)

Fig. 5. Prediction of diurnal cycles of PM redox activity (DTT assay) based on real time OC concentration. The minimum and maximum estimated DTT values were included within broken horizontal lines.

same as the predicted number of parameters), indicating that the regression equation has an appropriate number of predictors. Thus, $95 \%$ of the DTT concentration variance can be explained by the variance of this 3-parameters model. These results confirm our earlier observations that organics drive the DTT response (Ntziachristos et al., 2007a). According to Cho et al. (2005), this assay is relatively insensitive to trace elements, which is consistent with our regression results. Although the redox activity of transition metals in biological reactions is well established, the DTT assay does not reflect the redox activity for trace elements such as $\mathrm{Al}$ and Co. We hypothesize this could be due to the correlation of the trace metals with PAHs as indicated by Ntziachristos et al. (2007a). Al showed moderated correlation with light-MW PAHs $(R=0.46)$, suggesting $\mathrm{Al}$ concentrations in the regression model (Eq. 2) might serve as a surrogate for the effect of light-MW PAHs on the DTT activity levels. Co concentration is not well correlated with PAHs $(R=0.15)$; however, it is highly correlated with total OC $(R=0.59)$. The PAHs only accounts for a small fraction of total OC (less than $30 \mathrm{ppm}$ ). Therefore Co might be a surrogate for other organic species. It is possible that regression models using different selection criteria, including OC and PAHs as predictor variables, could explain the variability of DTT equally well.

The above best fitting regression equation (Eq. 2) can be used to estimate the effect of an increase/decrease in the concentration of any of the predictive variables (i.e. $\mathrm{OC}, \mathrm{Al}_{\text {soluble }}$ and $\left.\mathrm{Co}_{\text {soluble }}\right)$ on the DTT levels. For example, we var- ied OC over its typical average diurnal range at Site 2 (at the Wilmington site average hourly $\mathrm{OC}$ data were available only for May 2007), while holding constant the $\mathrm{Al}_{\text {soluble }}$ and $\mathrm{Co}_{\text {soluble }}$ concentrations to their average background levels (those measured at Site 5). This approach allowed us to describe/predict the DTT concentration at Site 2 as the sum of its "urban background" concentration and the enhancement due to an increase in OC. As shown in Fig. 5, the predicted DTT at Site 2 peaked during morning rush hour traffic because of increased motor-vehicle emissions, reached a minimum late in the afternoon, and slightly increased again at night because of a lowered mixing height and increased atmospheric stability. The DTT activity rates and OC concentrations were $\sim 4$ times higher between 09:00 and 11:00 a.m. than at 17:00-18:00 p.m., suggesting that traffic emissions may increase the potential of airborne particles to induce oxidative stress on human cells.

It should be noted that the intercept term influenced between 8 to $16 \%$ of the DTT levels predicted by Eq. (2), when considering the typical concentration range for OC in Wilmington. This small, but non-negligible effect of the intercept may be due to the contribution of redox active PM components, which are not included in our chemical analysis.

\subsection{2 "Best-fitting" model for ROS}

The "best-fitting" (2-parameters) regression equation for the ROS concentration was also obtained using a "forward" selection method in SAS ("PROC REG"): 
$\mathrm{ROS}=0.332+0.399 \cdot \mathrm{OC}+2.2 \times 10^{-04} \cdot \mathrm{V}_{\text {soluble }}$

where, $\mathrm{OC}$ and $\mathrm{V}_{\text {soluble }}$ are the measured concentrations of OC and water-soluble V, respectively. Similarly to DTT, the model was run considering all of the quasi-ultra-fine, accumulation and coarse concentrations together (a total of 16 data-points; 2 outliers were found and discarded), and the correlation between predicted and measured ROS was excellent (y [predicted ROS] $=0.93 \mathrm{X}$ [measured ROS] +0.075 ); $\left.R^{2}=0.93\right)$.

As shown in Table S5b (supporting information http://www.atmos-chem-phys.net/8/6439/2008/ acp-8-6439-2008-supplement.pdf), water-soluble $\mathrm{V}$ is the most influential factor in the regression (partial $R^{2}=0.86$ ). OC was also selected as a predictor variable (partial $R^{2}=0.07$ ). The overall model is statistically significant ( $p<0.0001$ ), with an $R^{2}$ of 0.93 , and a parameter coefficient (Cp) of 3 , which suggests that the regression equation has an appropriate number of predictors. Hence, $93 \%$ of the ROS concentration variance can be explained by the variance of this 2-parameters model. These results indicate that the ROS response depends on two variables, each of which is an indicator of two major sources in that Long Beach area: OC (vehicular traffic) and V (ship emissions and oil combustion). The rest of PM species considered in this analysis were either non-correlated to ROS or, if they showed a significant association with ROS, they were probably emitted by the same two major sources.

The best fitting regression equation for ROS (Eq. 3) could also be used to estimate the effect of an increase/decrease in the concentration of any of the predictive variables (i.e. OC or $\mathrm{V}_{\text {soluble }}$ ) on the ROS levels. However, because of the significant influence of $\mathrm{V}_{\text {soluble }}$ on ROS and of the lack of methodologies for near continuous measurements of particulate $\mathrm{V}$, we could not predict the average diurnal variation of ROS as we did for DTT.

We continue to confirm our earlier observations that organics are important and influence the redox properties of PM measured by the DTT assay. According to Cho et al. (2005), most trace elements do not mitigate this assay; therefore all of our results are internally consistent with our prior works. In contrast, the macrophage ROS assay is mainly a function of two PM species, OC and V, which are indicators of the two major sources dominating the study area, i.e. vehicular traffic and ship emissions, respectively.

\section{Summary and conclusions}

The redox properties of size fractionated PM samples collected in the Los Angeles-Long Beach port area were measured using: 1) a "biological" assay applied to water soluble extracts of the collected particles (Macrophage ROS assay), and: 2) a "chemical" assay performed on suspensions of the PM filter samples (DTT assay). Quasi-UF mode particles showed the highest redox activities at all sites, on both a per-mass and per-air volume basis, and the substantial correlation between these two assays $\left(R^{2}=0.61\right)$ suggests that both assays may be driven, at least in part, by variations in the concentrations of similar chemical species. A multiple linear regression model showed that OC (emitted from vehicle exhaust and port activities) was the single most important component influencing the DTT levels. A similar model also indicated that the variability of macrophage ROS is explained by changes in OC and water-soluble vanadium concentrations (from vehicular traffic and ship emissions/bunker oil combustion, respectively). The predicted DTT activity rates and measured OC concentrations at one of the port sites were $\sim 3-4$ times higher between 09:00 and 11:00 a.m. than at 17:00-18:00 p.m., confirming that traffic emissions can increase the redox potential of airborne PM substantially and induce oxidative stress on human cells. The DTT and ROS are two independent and intrinsically different assays that measure different aspects/modes of PM toxicity, and, in this respect, they complement each other. A better understanding of the relationships between size-segregated PM (and PM components) and the associated DTT and ROS activities is important in terms of public health management and prevention policies.

\section{Supplemental information}

Weekly averages of the PM mass and of major chemical components at each site and for 3 different size fractions, Pearson correlation coefficients between macrophage ROS (and DTT) and selected chemical species, Pearson coefficients among selected water-soluble elements, summary statistics for Figs. 4 and 5, concentrations of water-soluble elements, a map of the sampling sites, and the results of the linear regression between macrophage ROS and DTT are included in the Supplemental Information document (http://www.atmos-chem-phys.net/8/ 6439/2008/acp-8-6439-2008-supplement.pdf).

Acknowledgements. The study was supported by the Southern California Particle Center (SCPC), funded by US EPA under the STAR program (Grant RD-8324-1301-0) to the University of Southern California. The research described herein does not necessarily reflect the views of the agency, and no official endorsement should be inferred. Mention of trade names or commercial products does not constitute an endorsement or recommendation for use. We thank the staff at the Wisconsin State Lab of Hygiene (WSLH) for chemical and toxicological analysis of the PM samples, and the staff at UCLA for the DTT analysis of the PM samples. We are thankful for the Port of Long Beach, Dinesh Mohda and the staff at the Long Beach Job Corps Center, Balthazar Alvarez and South Coast AQMD for the help in the sample collection at the port sites.

Edited by: J. Abbatt 


\section{References}

Arhami, M., Sillanpää, M., Hu, S., Olson, M. R., Schauer, J. J., and Sioutas, C.: Size-Segregated Inorganic and Organic Components of PM in the Communities of the Long Beach and Los Angeles Harbor, Aerosol Sci. Technol., in press, 2008.

Birmili, W., Allen, A. G., Bary, F., and Harrison, R. M.: Trace Metal Concentrations and Water Solubility in Size-Fractionated Atmospheric Particles and Influence of Road Traffic, Environ. Sci. Technol., 40, 1144-1153, 2006.

Cho, A. K., Sioutas, C., Miguel, A. H., Kumagai, Y., Schmitz, D. A., Singh, M., Eiguren-Fernandez, A., and Froines, J. R.: Redox activity of airborne particulate matter at different sites in the Los Angeles Basin, Environ. Res., 99, 40-47, 2005.

Chowdhury, Z., Zheng, M., Schauer, J. J., Sheesley, R. J., Salmon, L. G., Cass, G. R., and Russell, A. G.: Speciation of ambient fine organic carbon particles and source apportionment of PM2.5 in Indian cities, J. Geophys. Res., 112(D15), D15303, doi:10.1029/2007JD008386, 2007.

Decesari, S., Facchini, M. C., Matta, E., Lettini, F., Mircea, M., Fuzzi, S., Tagliavini, E., and Putaud, J. P.: Chemical features and seasonal variation of fine aerosol water-soluble organic compounds in the Po Valley, Italy, Atmos. Environ., 35, 3691-3699, 2001.

Dockery, D. W., Pope III, D. C. A., Xu, X., Spengler, J. D., Ware, J. H., Fay, M. E., Ferris, B. G., and Speizer, F. E.: An Association between Air Pollution and Mortality in Six US Cities, N. Engl. J. Med., 329, 1753-1759, 1993.

Geller, M. D., Ntziachristos, L., Mamakos, A., Samaras, Z., Schmitz, D. A., Froines, J. R., and Sioutas, C.: Physicochemical and redox characteristics of particulate matter (PM) emitted from gasoline and diesel passenger cars, Atmos. Environ., 40, 6988-7004, 2006.

Goldsmith, C., Imrich, A., Danaee, H., Ning, Y., and Kobzik, L.: Analysis of air pollution particulate-mediated oxidant stress in alveolar macrophages, J. Toxicol. Environ. Health, Part A, 54, 529-545, 1998.

Heal, M. R., Hibbs, L. R., Agius, R. M., and Beverland, L. J.: Total and water-soluble trace metal content of urban background PM10, PM2.5 and black smoke in Edinburgh, UK, Atmos. Environ., 39, 1417-1430, 2005.

Herner, J. D., Green, P. G., and Kleeman, M. J.: Measuring the trace elemental composition of size-resolved airborne particles, Environ. Sci. Technol., 40, 1925-1933, 2006.

Ho, K. F., Lee, S. C., Cao, J. J., Li, Y. S., Chow, J. C., Watson, J. G., and Fung, K.: Variability of organic and elemental carbon, water soluble organic carbon, and isotopes in Hong Kong, Atmos. Chem. Phys., 6, 4569-4576, 2006,

http://www.atmos-chem-phys.net/6/4569/2006/.

Isakson, J., Persson, T. A., and Selin Lindgren, E.: Identification and assessment of ship emissions and their effects in the harbour of Goteborg, Sweden, Atmos. Environ., 35, 3659-3666, 2001.

Kerminen, V. M., Teinila, K., Hillamo, R., and Pakkanen, T.: Substitution of chloride in sea-salt particles by inorganic and organic anions, J. Aerosol Sci., 29, 929-942, 1998.

Kumagai, Y., Koide, S., Taguchi, K., Endo, A., Nakai, Y., Yoshikawa, T., and Shimojo, N.: Oxidation of Proximal Protein Sulfhydryls by Phenanthraquinone, a Component of Diesel Exhaust Particles, Chem. Res. Toxicol., 15, 483-489, 2002.

Landreman, A. P., Shafer, M., Hemming, J., Hannigan, M., and
Schauer, J. J.: A Macrophage-Based Method for the Assessment of the Oxidative Stress Activity of Atmospheric Particulate Matter (PM) and Application to Routine (Daily-24 h) Aerosol Monitoring Studies, Aerosol Sci. Technol., 42(11), 946-957, 2008.

Li, N., Sioutas, C., Cho, A., Schmitz, D., Misra, C., Sempf, J., Wang, M. Y., Oberley, T., Froines, J., and Nel, A.: Ultrafine particulate pollutants induce oxidative stress and mitochondrial damage, Environ. Health Perspect., 111, 455-460, 2003.

Lin, C. C., Chen, S. J., Huang, K. L., Hwang, W. I., ChangChien, G. P., and Lin, W. Y.: Characteristics of metals in nano/ultrafine/fine/coarse particles collected beside a heavily trafficked road, Environ. Sci. Technol., 39, 8113-8122, 2005.

Lu, G., Brook, J. R., Alfarra, M. R., Anlauf, K., Leaitch, W. R., Sharma, S., Wang, D., Worsnop, D. R., and Phinney, L.: Identification and characterization of inland ship plumes over Vancouver, BC, Atmos. Environ., 40, 2767-2782, 2006.

Miyazaki, Y., Kondo, Y., Takegawa, N., Komazaki, Y., Fukuda, M., Kawamura, K., Mochida, M., Okuzawa, K., and Weber, R. J.: Time-resolved measurements of water-soluble organic carbon in Tokyo, J. Geophys. Res., 111(D23), D23206, doi:10.1029/2006JD007125, 2006.

Mudway, I. S., Stenfors, N., Duggan, S. T., Roxborough, H., Zielinski, H., Marklund, S. L., Blomberg, A., Frew, A. J., Sandstrom, T., and Kelly, F. J.: An in vitro and in vivo investigation of the effects of diesel exhaust on human airway lining fluid antioxidants, Arch. Biochem. Biophys., 423, 200-212, 2004.

Nel, A., Diaz-Sanchez, D., and Li, N.: The role of particulate pollutants in pulmonary inflammation and asthma: evidence for the involvement of organic chemicals and oxidative stress., Curr. Opin. Pulm. Med., 7, 20-26, 2001.

Nel, A.: ATMOSPHERE: Enhanced: Air Pollution-Related Illness: Effects of Particles, Science, 308, 804-806, doi:10.1126/science.1108752, 2005.

Ntziachristos, L., Cho, A. K., Froines, J. R., and Sioutas, C.: Relationship between redox activity and chemical speciation of sizefractionated particulate matter, Particle and Fiber Toxicology, 4, 5, doi:10.1186/1743-8977-4-5, 2007a.

Ntziachristos, L., Ning, Z., Geller, M. D., Sheesley, R. J., Schauer, J. J., and Sioutas, C.: Fine, ultrafine and nanoparticle trace element compositions near a major freeway with a high heavy-duty diesel fraction, Atmos. Environ., 41, 5684-5696, 2007b.

Pio, C. A. and Lopes, D. A.: Chlorine loss from marine aerosol in a coastal atmosphere, J. Geophys. Res. D: Atmos., 103, $25263-$ $25272,1998$.

Polidori, A., Turpin, B. J., Lim, H.-J., Cabada, J. C., Subramanian, R., Pandis, S. N., and Robinson, A. L.: Local and Regional Secondary Organic Aerosol: Insights from a Year of Semi-Continuous Carbon Measurements at Pittsburgh, Aerosol Sci. Technol., 40, 861-872, 2006.

Pope, C. A., Burnett, R. T., Thun, M. J., Calle, E. E., Krewski, D., Ito, K., and Thurston, G. D.: Lung cancer, cardiopulmonary mortality, and long-term exposure to fine particulate air pollution, J. Am. Med. Assoc., 287, 1132-1141, 2002.

Pope, C. A., Burnett, R. T., Thurston, G. D., Thun, M. J., Calle, E. E., Krewski, D., and Godleski, J. J.: Cardiovascular mortality and long-term exposure to particulate air pollution - Epidemiological evidence of general pathophysiological pathways of disease, Circulation, 109, 71-77, 2004.

Prahalad, A. K., Soukup, J. M., Inmon, J., Willis, R., Ghio, A. J., 
Becker, S., and Gallagher, J. E.: Ambient Air Particles: Effects on Cellular Oxidant Radical Generation in Relation to Particulate Elemental Chemistry, Toxicol. Appl. Pharmacol., 158, 8191, 1999.

Rodhe, H.: Human impact on the atmospheric sulfur balance, Tellus Series a-Dynamic Meteorology and Oceanography, 51, 110-122, 1999.

Ruellan, S. and Cachier, H.: Characterisation of fresh particulate vehicular exhausts near a Paris high flow road, Atmos. Environ., 35, 453-468, 2001.

Schauer, J. J.: Evaluation of elemental carbon as a marker for diesel particulate matter, J. Expo. Anal. Environ. Epidemiol., 13, 443453, 2003.

Seagrave, J., Gigliotti, A., McDonald, J. D., Seilkop, S. K., Whitney, K. A., Zielinska, B., and Mauderly, J. L.: Composition, toxicity, and mutagenicity of particulate and semivolatile emissions from heavy-duty compressed natural gas-powered vehicles, Toxicol. Sci., 87, 232-241, 2005.

Seinfeld, J. H. and Pandis, S. N.: Atmospheric chemistry and physics: From air pollution to climate change, John Wiley, New York, 1998.

Sheesley, R. J., Schauer, J. J., Smith, N. D., and Hays, M. D. H.: Development of a standardized method for the analysis of organic compounds present in $\mathrm{PM}_{2.5}$, Procedings of 93rd A\&WMA Annual National Meeting, Salt Lake City, UT, 2000.
Sioutas, C., Delfino, R. J., and Singh, M.: Exposure assessment for atmospheric ultrafine particles (UFPs) and implications in epidemiologic research, Environ. Health Perspect., 113, 947-955, 2005.

Sullivan, A. P. and Weber, R. J.: Chemical characterization of the ambient organic aerosol soluble in water: 1. Isolation of hydrophobic and hydrophilic fractions with a XAD8 resin, J. Geophys. Res. D: Atmos., 111(D5), D05314, doi:10.1029/2005JD006485, 2006.

Turpin, B. J., Saxena, P., and Andrews, E.: Measuring and Simulating Particulate Organics in the Atmosphere: Problems and Propects., Atmos. Environ., 34, 2983-3013, 2000.

Weber, R. J., Sullivan, A. P., Peltier, R. E., Russell, A., Yan, B., Zheng, M., De Gouw, J., Warneke, C., Brock, C., Holloway, J. S., Atlas, E. L., and Edgerton, E.: A study of secondary organic aerosol formation in the anthropogenic-influenced southeastern United States, J. Geophys. Res., 112(D13), D13302, doi:10.1029/2007JD008408, 2007.

Zhang, Y., Schauer, J. J., Shafer, M. M., Hannigan, M. P., and Dutton, S. J.: Source Apportionment of in vitro Reactive Oxygen Species Bioassay Activity from Atmospheric Particulate Matter., Environ. Sci. Technol., 42(19), 7502-7509, 2008.

Zheng, M., Cass, G. R., Schauer, J. J., and Edgerton, E. S.: Source apportionment of PM2.5 in the southeastern United States using solvent-extractable organic compounds as tracers, Environ. Sci. Technol., 36, 2361-2371, 2002. 